\title{
Research Article \\ Effect of Heat Input on Microstructure and Hardness Distribution of Laser Welded Si-Al TRIP-Type Steel
}

\author{
Adam Grajcar, ${ }^{1}$ Maciej Różański, ${ }^{2}$ Sebastian Stano, ${ }^{2}$ \\ Aleksander Kowalski, ${ }^{1}$ and Barbara Grzegorczyk ${ }^{1}$ \\ ${ }^{1}$ Institute of Engineering Materials and Biomaterials, Silesian University of Technology, 18a Konarskiego Street, 44-100 Gliwice, Poland \\ ${ }^{2}$ Institute of Welding, 16/18 Bł. Czesława Street, 44-100 Gliwice, Poland \\ Correspondence should be addressed to Adam Grajcar; adam.grajcar@polsl.pl
}

Received 31 May 2013; Revised 22 October 2013; Accepted 22 October 2013; Published 22 January 2014

Academic Editor: Ming-Xing Zhang

Copyright (C) 2014 Adam Grajcar et al. This is an open access article distributed under the Creative Commons Attribution License, which permits unrestricted use, distribution, and reproduction in any medium, provided the original work is properly cited.

This study is concerned with issues related to laser welding of $\mathrm{Si}-\mathrm{Al}$ type TRIP steels with $\mathrm{Nb}$ and Ti microadditions. The tests of laser welding of thermomechanically rolled sheet sections were carried out using keyhole welding and a solid-state laser. The tests carried out for various values of heat input were followed by macro- and microscopic metallographic investigations as well as by microhardness measurements of welded areas. A detailed microstructural analysis was carried out in the penetration area and in various areas of the heat affected zone (HAZ). Special attention was paid to the influence of cooling conditions on the stabilisation of retained austenite, the most characteristic structural component of TRIP steels. The tests made it possible to determine the maximum value of heat input preventing the excessive grain growth in HAZ and to identify the areas of the greatest hardness reaching 520 HV0.1.

\section{Introduction}

Constantly rising prices of energy sources and environmental aspects force car manufacturers to reduce fuel consumption. The basic way to achieve this goal is to reduce a complete vehicle weight. To this end, manufacturers seek new grades of materials, mainly high-strength steels, enabling the significant reduction of cross sections of both structural and panelling materials. In addition, such materials should demonstrate technological processability, that is, primarily forming and welding. Recently, resistance welding is often replaced by laser welding. Materials which meet the aforesaid requirements include Advanced High-Strength Steels (AHSS) dedicated for automotive industry. They are one of the most important achievements of today's metallurgy. Depending on their microstructure, steels can be divided into dual phase steels (DP), complex phase steels (CP), martensitic steels (MS), and steels with the transformation induced plasticity effect (TRIP) [1-3].

The greatest prospects of development due to the effective combination of high strength and plasticity characterise multiphase TRIP-aided steels. The microstructure of these steels is composed of a ferritic matrix containing bainiticaustenitic islands with a dozen or so fraction of thermally stable retained austenite which, however, is mechanically unstable. The retained austenite undergoes a martensitic transformation [2-4], which partly takes place during the cold technological forming of sheets, in a car manufacture process. The remaining retained austenite undergoes a martensitic transformation only in the case of greater deformations, for example, caused during a car crash, by partly absorbing impact energy, thus increasing the passive safety of passengers. The required microstructure of TRIP-aided steel is obtained by properly adjusting their chemical composition in combination with a multistep heat treatment following cold rolling $[4,5]$. Currently produced TRIP steels have a diversified chemical composition with the total content of alloying elements amounting to even a few percentages by weight. A carbon content is from $0.1 \%$ up to $0.55 \%$ in medium-C TRIP steels. The greatest content of carbon is present in the retained austenite, being the reason for its stabilisation. Other important alloying elements are $\mathrm{Mn}$ 
(1\%-2.5\%), Si (0.2\%-2\%), and aluminium (0\%-1.5\%) [2-6]. In order to increase mechanical properties, new attempts include additions of $\mathrm{Mo}$ and microadditions of $\mathrm{Nb}, \mathrm{Ti}$, and $\mathrm{V}$, often supported by a thermomechanical treatment [4, $6]$.

One of the key groups of technological processes, without which it would be impossible to produce an advanced car body, is welding process of joining metal elements. At present, a dominant and very efficient process used for joining car body elements is resistance spot welding. The major problem accompanying AHSS resistance welding is the occurrence of brittle cracks in the joint plane caused by an increased content of $\mathrm{C}$ and alloying elements $(\mathrm{Mn}, \mathrm{Si}, \mathrm{Al}, \mathrm{Cr}$, and $\mathrm{Mo})$, responsible for the steel tendency to develop martensitic structures $[5,7,8]$. Pichler et al. [7] state that the maximum crack-preventing content of $\mathrm{P}$ in steel must be below $0.012 \%$. Despite many advantages such as high efficiency, resistance welding is increasingly often replaced by laser welding, which is successfully applied for joining steels and aluminium alloys which is very important in the manufacturing of cars [913]. The competitive advantages of laser welding include high power density, high process flexibility, and high welding rate with small distortion of elements being welded. In addition, a laser beam welding process is also easily applied in automated and robotised processes. Advanced variants of this method such as welding with a remote welding, make it possible to produce more than a dozen welds in a matter of seconds [14].

Problems accompanying AHSS laser welding are similar to those of resistance welding and are mainly due to a high joint cooling rate. Numerous works [15-17] point out the problems of the high hardness of welded joints and the related loss of the high plasticity of the material obtained through previous thermal or thermomechanical treatment. Zhang et al. [18] developed diagrams of supercooled austenite transformations for continuous cooling transformations (CCT) for five TRIP steel grades with a carbon equivalent $\mathrm{C}_{\mathrm{eq}}$ range of $0.44 \%-0.71 \%$. The diagrams expressly reveal that, for cooling rates corresponding to weld and HAZ cooling rates during laser welding, that is, approximately $1000^{\circ} \mathrm{C} \mathrm{s}^{-1}$ (cooling time $t_{800 / 500}$ of a metal between $800^{\circ} \mathrm{C}$ and $500^{\circ} \mathrm{C}$ can be shorter than $1 \mathrm{~s}$ ), it is not possible to obtain a microstructure characterised by high plasticity and hardness below $350 \mathrm{HV}$. The work in [19] presents weldability tests of TRIP steel with a very low carbon content and a high silicon and manganese content (0.11C-1.19Si-1.67Mn). The hardness of a weld and that of heat affected zone (HAZ) did not exceed $220 \mathrm{HV}$; it should however be noted that welds were made using the TIG method. In addition, decreasing the content of carbon in TRIP steels usually results in the reduction of a retained austenite fraction, and consequently in the lower use of a strain-induced martensitic transformation for increasing steel strength and ductility at the same time.

This work presents the results of tests aimed to determine the impact of laser welding heat input on the microstructure and microhardness of the fusion zone and on the HAZ of TRIP-type steel with silicon partly replaced by aluminium.
TABLE 1: Chemical composition of the investigated steel, wt.\%.

\begin{tabular}{cccccccccc}
\hline $\mathrm{C}$ & $\mathrm{Mn}$ & $\mathrm{Si}$ & $\mathrm{S}$ & $\mathrm{P}$ & $\mathrm{Nb}$ & $\mathrm{Ti}$ & $\mathrm{N}$ & $\mathrm{Al}$ & $\mathrm{C}_{\text {eq }}$ \\
\hline 0.24 & 1.55 & 0.87 & 0.004 & 0.010 & 0.030 & 0.023 & 0.0028 & 0.40 & 0.54 \\
\hline
\end{tabular}

Carbon equivalent $\mathrm{C}_{\mathrm{eq}}$ was calculated according to the formula $\mathrm{C}_{\mathrm{eq}}=\mathrm{C}+$ $(\mathrm{Mn} / 6)+(\mathrm{Si} / 24)+(\mathrm{Ni} / 40)+(\mathrm{Cr} / 5)+(\mathrm{Mo} / 4)[\%]$.

\section{Experimental Procedure}

The tests to determine the impact of the heat input of laser beam welding on the changes of microstructure and hardness in the fusion zone and HAZ involved the use of a $2 \mathrm{~mm}$ thick and $100 \mathrm{~mm}$ wide TRIP steel sheet. The chemical composition of the steel is presented in Table 1. Due to the negative impact of silicon on hot galvanising $[4,6]$, the concentration of Si was reduced from that most commonly applied to TRIP steels, that is, $1.5 \%$, to approximately $0.9 \%$. Silicon was partly replaced by a $0.4 \% \mathrm{Al}$ addition. $\mathrm{Nb}$ and $\mathrm{Ti}$ microadditions were used for forming dispersive carbonitrides favouring fine-grained microstructure and precipitation strengthening. It should increase strength properties of steel products. The sheet was manufactured applying thermomechanical rolling with controlled cooling to a room temperature directly from the final rolling temperature. The principal stage for the stabilisation of retained austenite was isothermal holding of the samples at $350^{\circ} \mathrm{C}$ for $600 \mathrm{~s}$. The details of the thermomechanical treatment are presented in [20].

The tests of laser-welded sections of TRIP steel sheets were carried out using the keyhole welding technique with a solid-state laser, integrated with a robotised laser treatment system, installed at Instytut Spawalnictwa in Gliwice, Poland. This station meets the requirements for advanced industrial stations and is equipped with

(i) laser TruDisk 12002, solid-state laser type Yb:YAG manufactured by the Trumpf company, with the maximum power being $12 \mathrm{~kW}$ and the quality of a laser beam designated by the parameter $\mathrm{BPP} \leq$ $8 \mathrm{~mm} \cdot \mathrm{mrad}$ (Figure 1(a));

(ii) head CFO manufactured by the Trumpf company (Figure 1(b)) connected with a laser source by means of an optical fibre with a diameter of $200 \mu \mathrm{m}$ and a focusing lens with a focal length fog $=300 \mathrm{~mm}$. The laser beam focus diameter was $300 \mu \mathrm{m}$.

In order to ensure the precise positioning of a laser beam on the surface subjected to remelting, the sheet was fixed by means of the system of eccentric clamps to a table being an integral part of the station. In order to ensure remelting conditions close to those of welding, it was necessary to apply parameters ensuring full penetration. Seven sheet welding tests were carried out using the parameters presented in Table 2. For four laser beam power levels $(2,3,4$, and $7 \mathrm{~kW})$, head travel rates (welding rates) were adjusted so that it was possible to obtain complete material penetration. For a laser beam power level of $4 \mathrm{~kW}$ (a power level corresponding to industrial standards applied today), tests were carried out at various laser head travel rates. The tests were carried out without a shielding gas in the air atmosphere. As a result, 
TABle 2: Parameters of steel sheet laser welding.

\begin{tabular}{lccccccc}
\hline Sample number & 1 & 2 & 3 & 4 & 5 & 6 & 7 \\
\hline Beam power, $\mathrm{kW}$ & 7 & 2 & 3 & 4 & 4 & 4 & 4 \\
Welding rate, $\mathrm{mm} / \mathrm{s}$ & 125 & 41.7 & 58.3 & 75.0 & 83.3 & 91.7 & 100 \\
Heat input, $\mathrm{kJ} / \mathrm{mm}$ & 0.056 & 0.048 & 0.051 & 0.053 & 0.048 & 0.043 \\
\hline
\end{tabular}

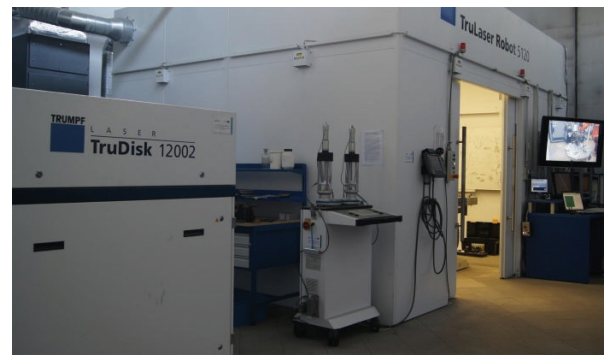

(a)

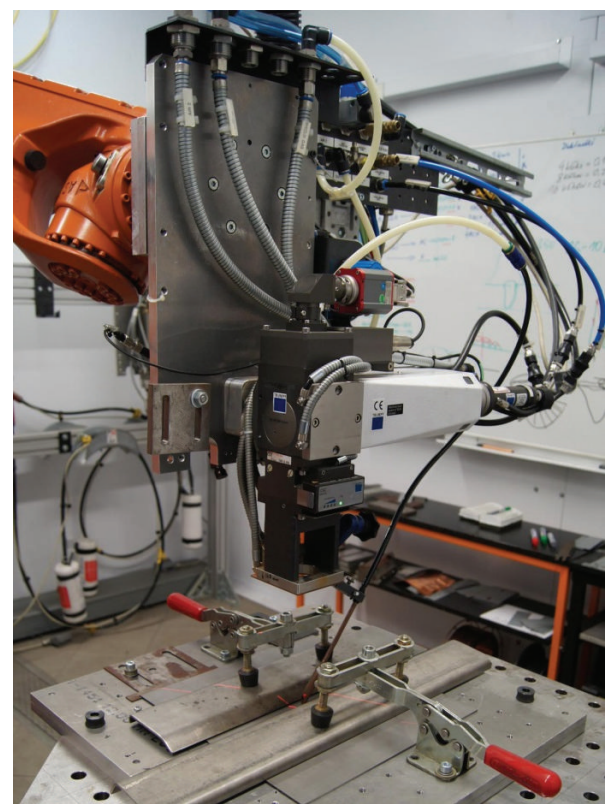

(b)

FIGURE 1: Disk laser TruDisk 12002 integrated with robotised station. Main view of station (a) and CFO head for laser beam keyhole welding (b).

it was possible to simulate a laser welding process with a scanning beam, in which usually, if the result of a welding process meets appropriate quality requirements, a shielding gas is not applied.

The sheet welding tests were followed by the visual inspection and the assessment of the penetration geometry from the weld face and weld root sides. Afterwards, the samples were cut in the plane perpendicular to the penetration axis and prepared for macro- and microscopic metallographic tests as well as for microhardness measurements on the cross section of penetrations. The preparation consisted in the inclusion of samples in epoxy resin, grinding with abrasive papers $(80,320,1000$, and 2500) and polishing by means of polishing cloth with an addition of diamond and corundum slurry with a grain size of 3 and $0.05 \mu \mathrm{m}$, respectively. The microstructure of the sample was revealed by etching in the aqueous solution of sodium pyrosulfate and next in 3\% Nital. The metallographic tests were carried out using a light microscope MeF4A manufactured by the Leica company. Microhardness measurements (HV0.1) were carried out using a microhardness tester Future-Tech FM700 , by means of the Vickers method and applying a load of $1 \mathrm{~N}$.

\section{Results and Discussion}

3.1. Visual Tests. The visual tests revealed the invariable geometry of the penetration along its whole length. In the case of sample number 1, due to too high power density obtained in the area affected by the laser beam, it was possible to observe a very turbulent remelting process. The material was locally divided along the run trajectory, as was the case with laser cutting. In the case of the remaining penetrations (designated as numbers 2-7), it was possible to observe very intense covering of both face and root with a glasslike layer of manganese, silicon, and aluminium oxides. A probable reason for this intense $\mathrm{Mn}, \mathrm{Si}$, and $\mathrm{Al}$ oxidation was the fact that the process was conducted in the air atmosphere, without a shielding gas. It was also possible to observe the lowering of a penetration run face.

3.2. Macroscopic Metallographic Tests. The macroscopic metallographic tests were carried out for samples 2-7. In each case, the width of penetration and that of HAZ were measured in the mid-length of a sheet. The measurement results related to the changes of the penetration width and the width of HAZ as the function of the heat input of a process are presented in Figure 2. The results obtained reveal that an increase in heat input is accompanied by an increase in the width of penetration and that of HAZ. Welding carried out with the lowest heat input $(0.037 \mathrm{~kJ} / \mathrm{mm})$ reveals the smallest width of penetration and of HAZ, 0.66 and $0.32 \mathrm{~mm}$, respectively. The greatest penetration width was that of the sample made with a heat input of $0.051 \mathrm{~kJ} / \mathrm{mm}$. In turn, the greatest width of HAZ characterised the welding conducted with a heat input of $0.053 \mathrm{~kJ} / \mathrm{mm}$ (Figure 2). Further increasing of the process heat input using the technological head with specified parameters caused a metal division phenomenon.

The microscopic tests and the measurements of microhardness on the cross section involved the use of good-quality penetrations, that is, without undercuts and excessive metal evaporation, made with the smallest, greatest, and intermediate heat input of the process of $0.037 \mathrm{~kJ} / \mathrm{mm}$ - sample 7 , 


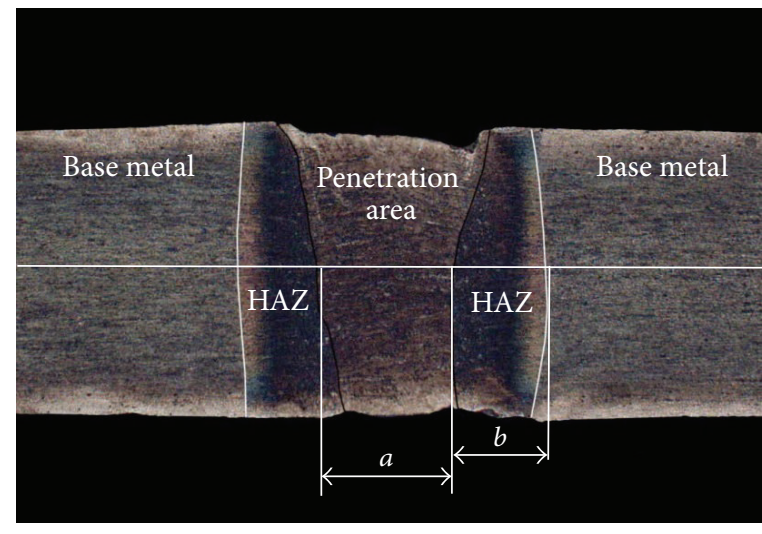

\begin{tabular}{lcccccc}
\hline $\begin{array}{l}\text { Fusion } \\
\text { number }\end{array}$ & 2 & 3 & 4 & 5 & 6 & 7 \\
\hline$a(\mathrm{~mm})$ & 0.75 & 0.82 & 0.80 & 0.73 & 0.72 & 0.66 \\
\hline$b(\mathrm{~mm})$ & 0.41 & 0.44 & 0.45 & 0.41 & 0.35 & 0.32 \\
\hline
\end{tabular}

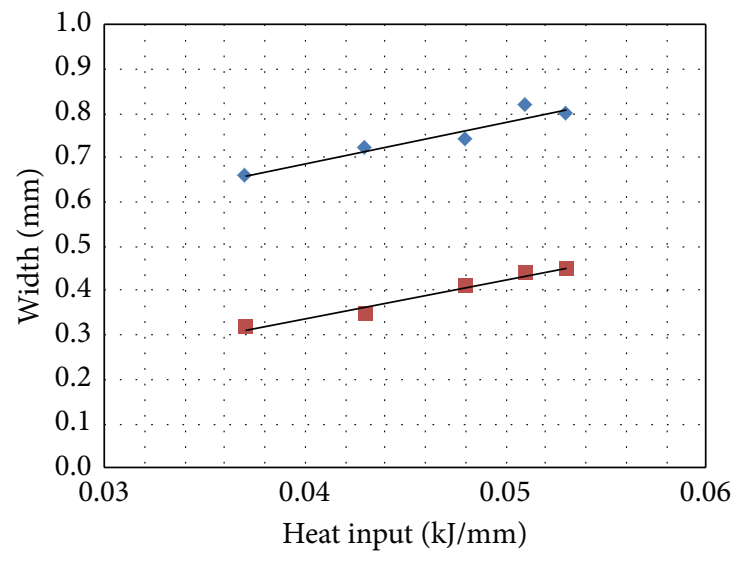

$\rightarrow a$

$b$

FIGURE 2: Area of measurement of penetration width and HAZ width in tested samples and measurement results.

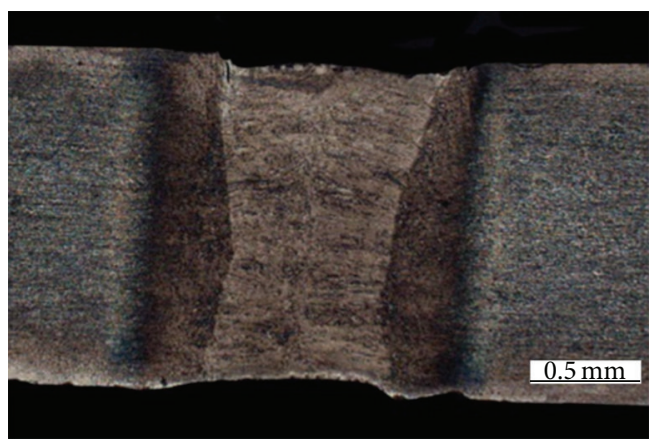

(a)

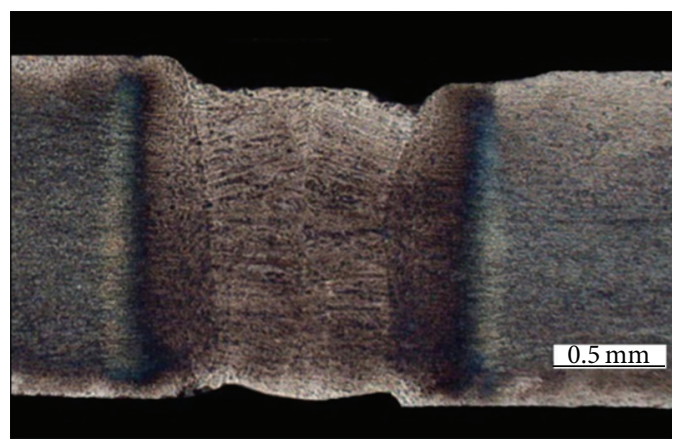

(b)

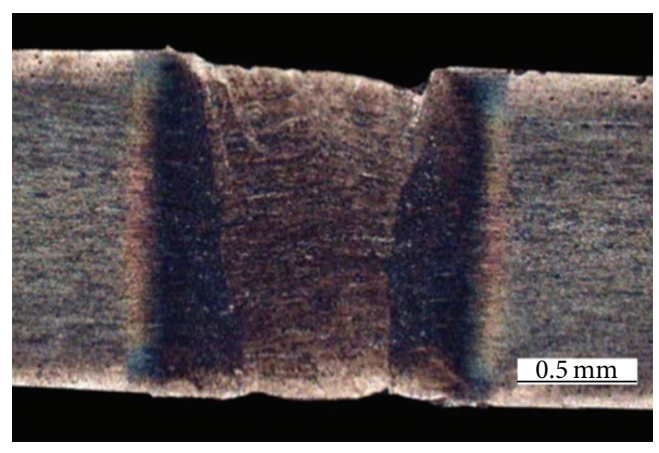

(c)

FIGURE 3: Macrostructure of penetration areas made with process heat input of $0.051 \mathrm{~kJ} / \mathrm{mm}(\mathrm{a}) ; 0.043 \mathrm{~kJ} / \mathrm{mm}(\mathrm{b}) ; 0.037 \mathrm{~kJ} / \mathrm{mm}(\mathrm{c})$.

$0.051 \mathrm{~kJ} / \mathrm{mm}$-sample 3, and $0.043 \mathrm{~kJ} / \mathrm{mm}$ - sample 6 . The macrostructures presented in Figure 3 are characterised by columnar crystals arranged in parallel with the direction of the fastest heat offtake, that is, perpendicularly to the penetration axis. The columnar crystals reach the middle of the molten area.
3.3. Microstructural Characteristics of Base Material and HAZ. The microstructure of the base material after thermomechanical rolling is a fine-grained, approximately $60 \%$ fraction, ferritic matrix $(\alpha)$ with regularly arranged bainitic-austenitic islands (B-A) (Figure 4(a)). The fraction of retained austenite $\left(f_{\gamma 0}\right)$ determined by means of an X-ray examination in [20] 


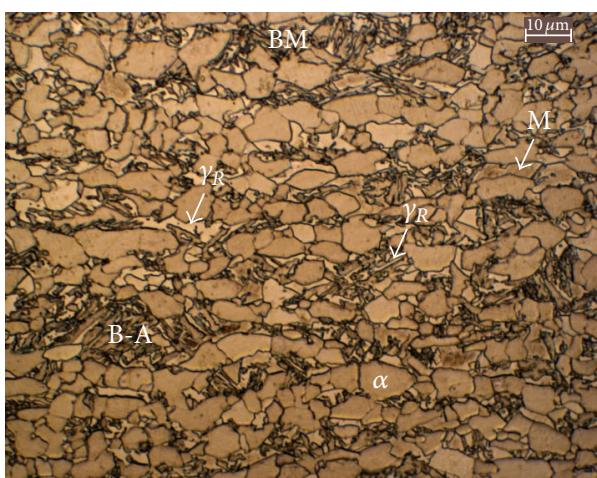

(a)

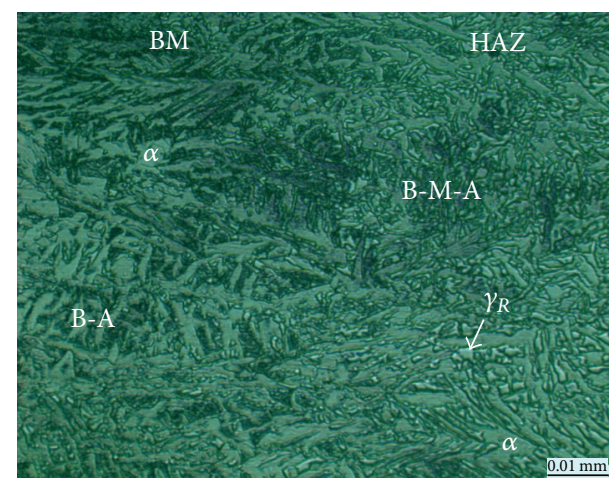

(b)

FIGURE 4: Ferritic-bainitic microstructure containing retained austenite of the base metal (BM) (a) and an intermediate zone between a base metal and HAZ containing an increased fraction of blocky retained austenite grains (b); $\alpha$ : ferrite, $\gamma_{R}$ : retained austenite, B-A: bainiticaustenitic regions, $\mathrm{M}$ : martensite, B-M-A: bainitic-martensitic-austenitic regions.

amounts to approximately 0.151 , whereas the content of carbon in this phase $\left(C_{\gamma 0}\right)$ is $1.23 \%$. The product of volume fraction and carbon concentration $\left(f_{\gamma 0} \times C_{\gamma 0}\right)$ is the total amount of carbon retained in the austenite and is often regarded as a measure for the TRIP effect [21-23]. For many Si-alloyed TRIP steels, a ratio of total carbon content to $C$ concentration in steel $\left(f_{\gamma 0} \times C_{\gamma 0}\right) / C$ is about 0.5 [21]. On the other hand, Sugimoto et al. [22] found that the ratio is increased to about 0.7 in $0.2 \mathrm{C}-1.5 \mathrm{Mn}-1 \mathrm{Si}-0.5 \mathrm{Al}$ alloys due to aluminium addition. The similar value of the $\left(f_{\gamma 0} \times C_{\gamma 0}\right) / C$ ratio $\sim 0.71$ was reported by Wang et al. [24]. The positive effect of $\mathrm{Al}$ addition on increasing a carbon concentration in retained austenite was also confirmed by Zhao et al. [23]. They measured that the carbon content in the $\gamma$ phase reaches almost all carbon in the $0.2 \mathrm{C}-1.5 \mathrm{Mn}-1.8 \mathrm{Al}$ steel. The ratio of total carbon concentration to $C$ content in the investigated $0.24 \mathrm{C}-1.5 \mathrm{Mn}-0.9 \mathrm{Si}-0.4 \mathrm{Al}-\mathrm{Nb}$ steel $\left(f_{\gamma 0} \times C_{\gamma 0}\right) / C$ is about 0.77 , which is in good agreement with the results obtained by other authors. The martensite start temperature of $\gamma$ phase amounts to approximately $-28^{\circ} \mathrm{C}$, ensuring the thermal stability of the $\gamma$ phase after cooling steel to the room temperature. The average size of ferrite grains is approximately $7 \mu \mathrm{m}$. The retained austenite $\left(\gamma_{R}\right)$ is located on the grain boundaries of the phase $\alpha$, in the form of irregular, bright grains with a size of up to approximately $5 \mu \mathrm{m}$. A significant amount of the austenite is located in the bainitic islands. The phase $\gamma$ present on the edges of the bainitic islands usually has the shape of pointed grains with a size of up to $2 \mu \mathrm{m}$. In turn, in the central part of B-A islands austenite has the form of thin layers located between the laths of bainitic ferrite. Some austenite grains in the ferritic matrix are elongated in the direction of rolling, which indicates that they were formed as a result of significant strain accumulation at a low final rolling temperature of $850^{\circ} \mathrm{C}$.

Figure 4(b) presents the microstructure of steel in the transition area between the base metal and the heat affected zone of the sample subjected to welding with a heat input of $0.037 \mathrm{~kJ} / \mathrm{mm}$. It is possible to observe an increase in the fraction of retained austenite bright grains of different sizes located in the ferritic-bainitic matrix. The fraction of polygonal ferrite decreases along with an increasing fraction of acicular ferrite and bainite. A decrease in the fraction of polygonal ferrite corresponds to an increasing temperature in the intercritical range $A_{c 1}-A_{c 3}$. The appearance of acicular ferrite and bainite is connected with a high cooling rate following laser treatment. This cooling rate is between $200^{\circ} \mathrm{C} \mathrm{s}^{-1}$ and $300^{\circ} \mathrm{Cs}^{-1}$, whereas the cooling time $t_{800 / 500}$ of a metal between $800^{\circ} \mathrm{C}$ and $500^{\circ} \mathrm{C}$ is about $1 \mathrm{~s}[10,14]$. It should be noted that these parameters are dependent on many factors: heat input, geometry and thickness of a joint, heat abstraction, and so forth. Moreover, it is very difficult to measure a temperature of the liquid metal using the keyhole welding technique. Concluding, the temperature at the fusion zone exceeded considerably the melting point of steel, whereas at the heat affected zone adjacent to the fusion weld it was much higher than $A_{c 3}$ of the steel. With increasing a distance from the $\mathrm{HAZ}$, a temperature decreases gradually below $A_{c 3}$. Going through a two-phase range enriches austenite in carbon and increases the possibility of its thermal stabilisation to the room temperature. A similar phenomenon was also observed by Amirthalingam et al. [25] in C-Mn-Si type and particularly in C-Mn-Al type TRIP steels. It can be expected that a significant fraction of bright grains underwent a partial martensitic or bainitic transformation during cooling, thus constituting bainiticmartensitic areas with retained austenite (B-M-A).

\subsection{Microstructural Characteristics of Laser-Welded and HAZ} Zones. Fusion zones and heat affected zones (HAZ) of samples subjected to laser treatment with various heat input values are presented in Figure 5. The fusion zones (Figures 5(a), 5(c), and 5(e)) contain primarily a lath martensitic microstructure, although in some areas retained austenite can be expected $\left(\gamma_{R}\right)$. It is very difficult to detect the retained austenite in the fusion zone. Kobayashi et al. [26] revealed that the $\gamma$ phases are fine and are located on the interlath boundary of the narrow martensite lath structure in $0.2 \mathrm{C}$ $1.5 \mathrm{Mn}-1.5 \mathrm{Si}$ steel. The unequivocal identification of retained austenite in the fusion zone requires a more detailed research 


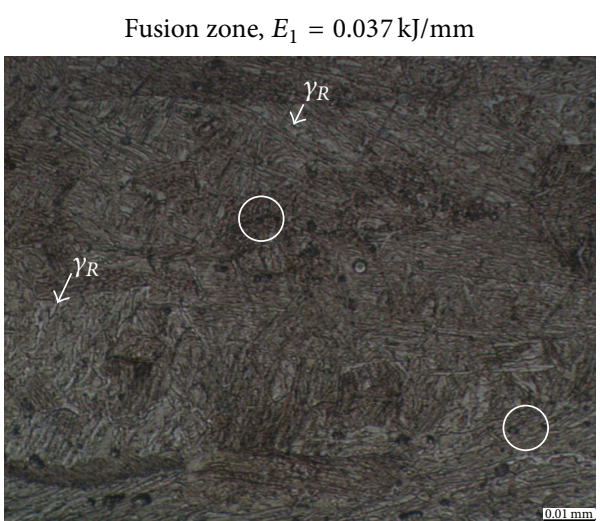

(a)

Fusion zone, $E_{1}=0.043 \mathrm{~kJ} / \mathrm{mm}$

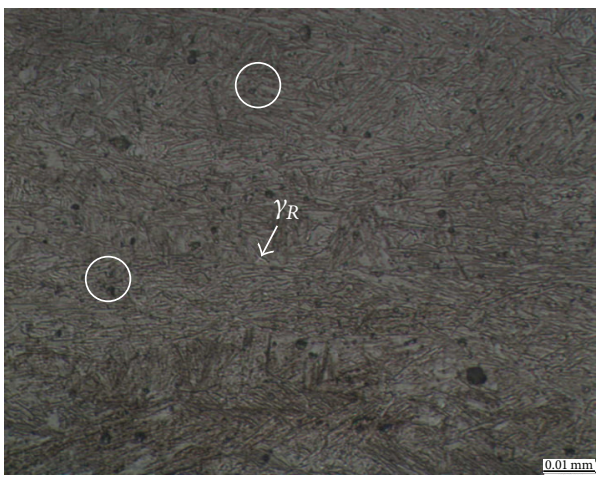

(c)

Fusion zone, $E_{1}=0.051 \mathrm{~kJ} / \mathrm{mm}$

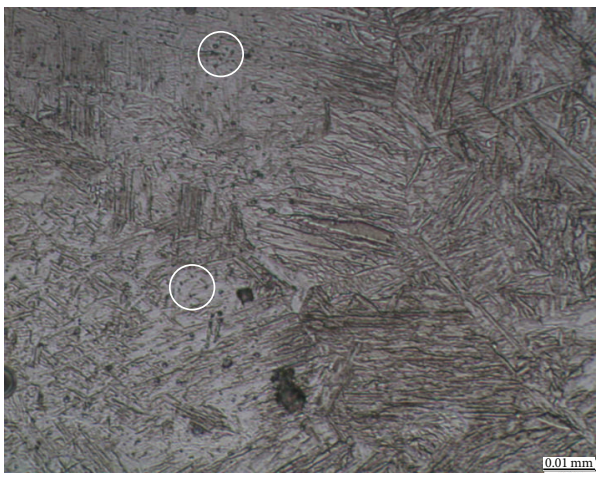

(e)
$\mathrm{HAZ}, E_{1}=0.037 \mathrm{~kJ} / \mathrm{mm}$

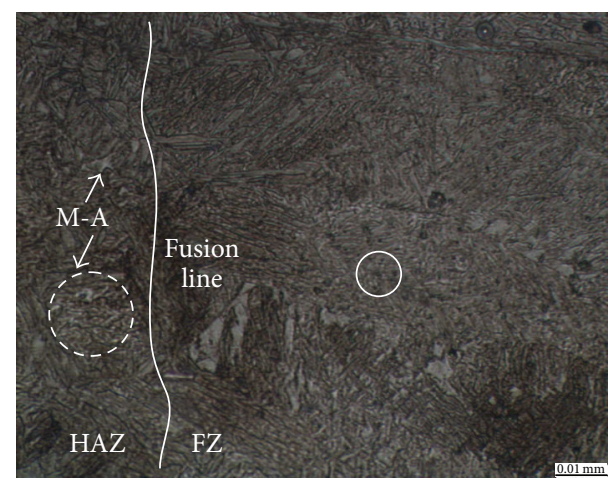

(b)

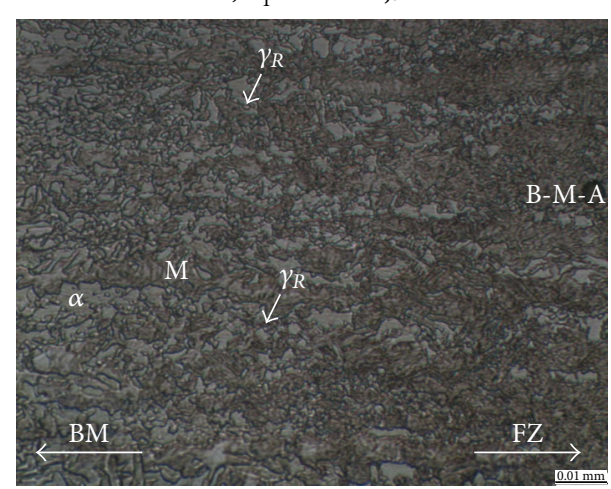

(d)

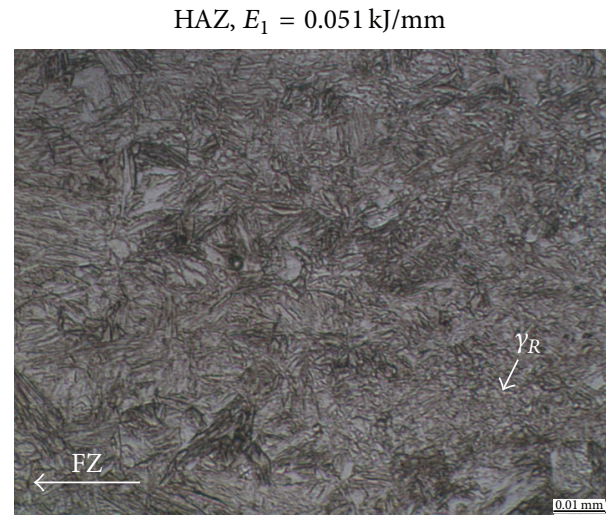

(f)

Figure 5: Microstructures of fusion zones (a), (c), and (e) and HAZ (b), (d), and (f) registered for the various heat input values; FZ: fusion zone, HAZ: heat affected zone, BM: base metal, $\alpha$ : ferrite, $\gamma_{R}$ : retained austenite, M-A: martensitic-austenitic constituents, M: martensite, B-M-A: bainitic-martensitic-austenitic regions; white circles indicate nonmetallic inclusions.

including SEM-EBSD and TEM techniques. The grain size increases with the increasing heat input of a process. It is especially visible for a sample welded at a heat input of $0.051 \mathrm{~kJ} / \mathrm{mm}$. The average grain size of prior austenite grains is about $40 \mu \mathrm{m}$. The grain size is still relatively small, which should be attributed to the presence of partially undissolved carbonitrides $\mathrm{Nb}$ and $\mathrm{Ti}$ [20]. The consequence of the process being conducted in the air atmosphere is the presence of numerous nonmetallic inclusions (marked by white circles) characterised by various sizes, which are accidentally arranged in the fusion zone. It is known that the reaction during welding affecting a final weld microstructure is inclusion formation. It is also known that the reaction between the dissolved alloying elements in the weld pool with the available oxygen, nitrogen (from the atmosphere), and carbon from base metal forms nonmetallic inclusions [13]. Taking into account the chemical composition of the investigated steel, it is very possible that the formations 


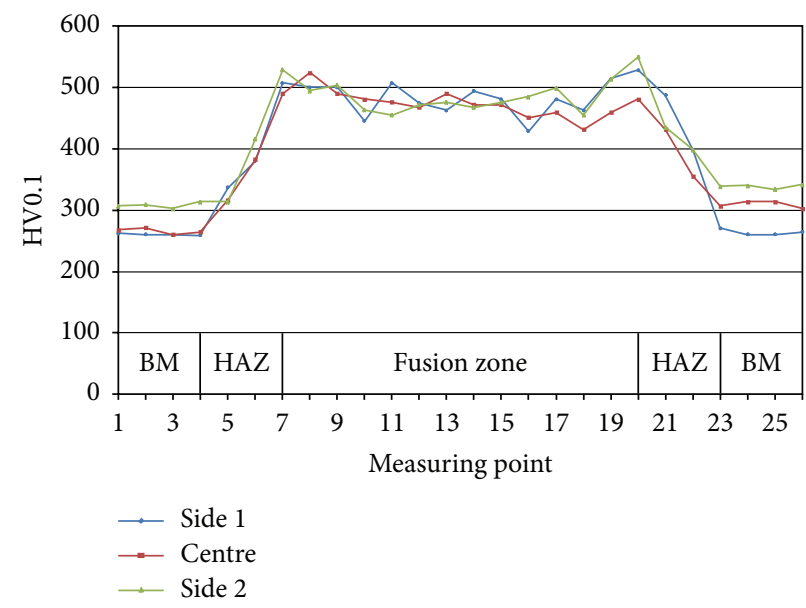

FIGURE 6: Microhardness values of a sample welded at a heat input of $0.051 \mathrm{~kJ} / \mathrm{mm}$ measured along three lines of the cross section (at a centre of the sheet thickness and near top and bottom surfaces).

indicated in Figure 5 are silicone and aluminium oxides but this will be investigated in the further work using EDS. The complex oxide-sulfide inclusions can be also expected as reported in Si-Al TRIP steels by other authors [13].

The micrographs in Figures 5(b), 5(d), and 5(f) show $\mathrm{HAZ}$ at various distances from the fusion zone. For instance, Figure 5(b) presents the microstructure of the sample subjected to laser treatment with the lowest heat input of $0.037 \mathrm{~kJ} / \mathrm{mm}$ in the area close to the fusion line. The HAZ area adjacent to the fusion line is characterised by the microstructure of lath martensite. It is possible to locally observe the bright particles or the areas of M-A (martensitic-austenitic) constituents. Similar microstructures of lath martensite with locally present retained austenite were observed for all the values of heat input. The size of martensitic areas in HAZ decreases along with an increasing distance from the fusion zone, which is determined by the temperature of steel heating during the process (Figure 5(f)). A further increase in the distance from the fusion zone is accompanied by the presence of bainitic-martensitic areas with retained austenite (B-M-A) decorated with ferrite grains (Figure 5(d)). The fraction of martensite decreases along with a decreasing distance from the base metal $(\mathrm{BM})$. This phase is surrounded by ferrite grains and numerous fine grains of retained austenite $\left(\gamma_{R}\right)$. Revealing the microstructural details of retained austenite requires the application of SEM and X-ray examination.

3.5. Microhardness Distribution across the Laser-Treated Zone. The average hardness of the base metal is relatively high and amounts to approximately $300 \mathrm{HV} 0.1$. Such hardness results from the presence of strengthening B-A type islands and thermomechanical processing. The example of hardness distribution along the cross section of the sample welded with a heat input of $0.051 \mathrm{~kJ} / \mathrm{mm}$ is presented in Figure 6 . The figure shows three lines corresponding to measurements carried out in the middle of the sheet thickness as well as in the upper and lower surfaces. No differences in microhardness depending on the distance from the sheet surface were observed. The aforesaid observation indicates the homogeneity of microstructure across the sample thickness. In addition, the course of microhardness, as to the shape and values obtained, is independent from the heat input applied. For this reason, a detailed analysis was carried out for a selected case. The curve presents an increase in hardness from approximately 300 to $520 \mathrm{HV} 0.1$, which results from the gradual reduction of the polygonal ferrite fraction and an increase in the fraction of bainitic and martensitic constituents. The greatest hardness of 500-520 HV0.1 is observed in HAZ. A slight decrease in hardness to $450-480$ HV0.1 can be observed in the fusion zone, which can be probably attributed to the total dissolution of $\mathrm{Nb} / \mathrm{Ti}$ carbonitrides and related disappearance of precipitation strengthening resulting from disperse particles of these precipitates.

The hardness is constant throughout the width of the fusion zone; this is due to the homogenous structure of columnar grains in the whole fusion zone (Figure 3). Due to a higher content of $\mathrm{C}$ and alloying elements, the hardness obtained is higher than that in the case of DP steels [11]. On the other hand, the hardness is lower than that in the case of resistance welded TRIP steel type 0.3C-1.5Mn-1.2Al-0.3Si [8].

\section{Conclusions}

A very dynamic thermal cycle of laser welding and the chemical composition of the base metal have the most significant impact on the structural changes and hardness of welded joints. A carbon content increased to $0.24 \%$ and the total concentration of alloying elements of $2.8 \%$ determine obtaining martensitic microstructures in the fusion zone and HAZ. A significant fraction of hard structural constituents results in a hardness increase to approximately $520 \mathrm{HV} 0.1$ in HAZ and approximately $480 \mathrm{HV} 0.1$ in the fusion zone. The heat input applied from the range $0.037-0.053 \mathrm{~kJ} / \mathrm{mm}$ has no significant impact on the microstructure and microhardness of the laser-penetrated area. Taking into account the fact that the width of HAZ and that of FZ increases along with 
increasing heat input as well asthe fact that a heat input of $0.051 \mathrm{~kJ} / \mathrm{mm}$ causes the excessive grain growth, the value of this parameter should be limited to about $0.045 \mathrm{~kJ} / \mathrm{mm}$. Such an approach guarantees obtaining good-quality penetrations, that is, without undercuts, porosity, and excessive metal evaporation. In order to prevent the formation of hard nonmetallic inclusions observed in the fusion zone, which might adversely affect the operating properties of welded joints, welding should be conducted in the atmosphere of a lower oxidising capacity. It is possible to reduce the HAZ and FZ hardness by applying, for example, bifocal welding technique or change laser beam focus which, as a result, should decrease a cooling rate and create the possibility of stabilising a greater fraction of ductile retained austenite in a welded joint.

\section{Conflict of Interests}

The authors declare that there is no conflict of interests regarding the publication of this paper.

\section{References}

[1] V. F. Zackay, E. R. Parker, D. Fahr, and R. Bush, "The enhancement of ductility in high-strength steels," Transactions of the ASM, vol. 60, pp. 252-257, 1967.

[2] O. Matsumura, Y. Sakuma, and H. Takechi, "TRIP and its kinetics aspects in austempered 0.4C-1.5Si-0.8Mn steel," Scripta Metallurgica, vol. 21, no. 10, pp. 1301-1306, 1987.

[3] O. Matsumura, Y. Sakuma, and H. Takechi, "Retained austenite in $0.4 \mathrm{C}-\mathrm{Si}-1.2 \mathrm{Mn}$ steel sheet intercritically heated and austempered," ISIJ International, vol. 27, no. 9, pp. 570-579, 1992.

[4] D. Krizan and B. C. De Cooman, "Analysis of the strain-induced martensitic transformation of retained austenite in cold rolled micro-alloyed TRIP steel," Steel Research International, vol. 79, no. 7, pp. 513-522, 2008.

[5] J. Senkara, "Contemporary car body steels for automotive industry and technological guidelines of their pressure welding," Welding International, vol. 3, pp. 184-189, 2013.

[6] A. Grajcar, R. Kuziak, and W. Zalecki, "Third generation of AHSS with increased fraction of retained austenite for the automotive industry," Archives of Civil and Mechanical Engineering, vol. 12, no. 3, pp. 334-341, 2012.

[7] A. Pichler, S. Traint, T. Hebesberger, P. Stiaszny, and E. A. Werner, "Processing of thin sheet multiphase steel grades," Steel Research International, vol. 78, no. 3, pp. 216-223, 2007.

[8] L. Cretteur, A. I. Koruk, and L. Tosal-Martínez, "Improvement of weldability of TRIP steels by use of in-situ pre- and post-heat treatments," Steel Research, vol. 73, no. 6-7, pp. 314-319, 2002.

[9] A. El-Batahgy and M. Kutsuna, "Laser beam welding of AA5052, AA5083, and AA6061 aluminum alloys," Advances in Materials Science and Engineering, vol. 2009, Article ID 974182, 9 pages, 2009.

[10] A. Lisiecki, "Diode laser welding of high yield steel," in Laser Technology 2012: Application of Lasers, vol. 8703 of Proceedings of SPIE, 2013.

[11] M. St. Weglowski, S. Stano, K. Krasnowski, M. Lomozik, K. Kwiecinski, and R. Jachym, "Characteristics of laser welded joints of HDT580X steel," Materials Science Forum, vol. 638642, pp. 3739-3744, 2010.
[12] J. Huang, M. Li, Z. Li, Y. Zhao, H. Li, and Y. Wang, "Influence of welding parameters on weld formation and microstructure of dual-laser beams welded T-Joint of aluminum alloy," Advances in Materials Science and Engineering, vol. 2011, Article ID 767260, 6 pages, 2011.

[13] M. Amirthalingam, M. Hermans, and I. Richardson, "Microstructural development during welding of silicon- and aluminum-based transformation-induced plasticity steels-inclusion and elemental partitioning analysis," Metallurgical and Materials Transactions A, vol. 40, no. 4, pp. 901-909, 2009.

[14] S. Stano, "New solid-state lasers and their application in welding as generators of laser radiation," Welding International, vol. 21, no. 3, pp. 173-179, 2007.

[15] S. S. Nayaki, V. H. B. Hernandez, and Y. Okita, "Microstructurehardness relationship in the fusion zone of TRIP steel welds," Materials Science and Engineering A, vol. 551, pp. 78-83, 2012.

[16] H. Cramer, P. Limley, and H. Blinzler, "Influence of the component geometry and the alloying elements on the fabrication weldability of steels for laser-beam welding," Welding and Cutting, vol. 55, no. 5, pp. 290-294, 2003.

[17] R. S. Sharma and P. Molian, "Weldability of advanced high strength steels using an Yb: YAG disk laser," Journal of Materials Processing Technology, vol. 211, no. 11, pp. 1888-1897, 2011.

[18] M. Zhang, L. Li, R. Y. Fu, D. Krizan, and B. C. De Cooman, "Continuous cooling transformation diagrams and properties of micro-alloyed TRIP steels," Materials Science and Engineering A, vol. 438-440, pp. 296-299, 2006.

[19] M. Zhang, L. Li, R.-Y. Fu, J.-C. Zhang, and Z. Wan, "Weldability of low carbon transformation induced plasticity steel," Journal of Iron and Steel Research International, vol. 15, no. 5, pp. 61-65, 2008.

[20] A. Grajcar, Structure of the C-Mn-Si-Al Steel Formed with StrainInduced Martensitic Transformation, Wydawnictwo Politechniki Śląskiej, Gliwice, Poland, 2009, (Polish).

[21] K.-I. Sugimoto, M. Tsunezawa, T. Hojo, and S. Ikeda, "Ductility of 0.1-0.6C-1.5Si-1.5Mn ultra high-strength TRIP-aided sheet steels with bainitic ferrite matrix," ISIJ International, vol. 44, no. 9, pp. 1608-1614, 2004.

[22] K.-I. Sugimoto, B. Yu, Y.-I. Mukai, and S. Ikeda, "Microstructure and formability of aluminum bearing TRIP-aided steels with annealed martensite matrix," ISIJ International, vol. 45, no. 8, pp. 1194-1200, 2005.

[23] L. Zhao, N. H. Van Dijk, E. Brück, J. Sietsma, and S. van der Zwaag, "Magnetic and X-ray diffraction measurements for the determination of retained austenite in TRIP steels," Materials Science and Engineering A, vol. 313, no. 1-2, pp. 145-152, 2001.

[24] X. D. Wang, B. X. Huang, L. Wang, and Y. H. Rong, "Microstructure and mechanical properties of microalloyed high-strength transformation-induced plasticity steels," Metallurgical and Materials Transactions A, vol. 39, no. 1, pp. 1-7, 2008.

[25] M. Amirthalingam, M. J. M. Hermans, L. Zhao, and I. M. Richardson, "Quantitative analysis of microstructural constituents in welded transformation-induced-plasticity steels," Metallurgical and Materials Transactions A, vol. 41, no. 2, pp. 431-439, 2010.

[26] J. Kobayashi, S. M. Song, and K. Sugimoto, "Microstructure and retained austenite characteristics of ultra high-strength TRIPaided martensitic steels," ISIJ International, vol. 52, no. 6, pp. 1124-1129, 2012. 

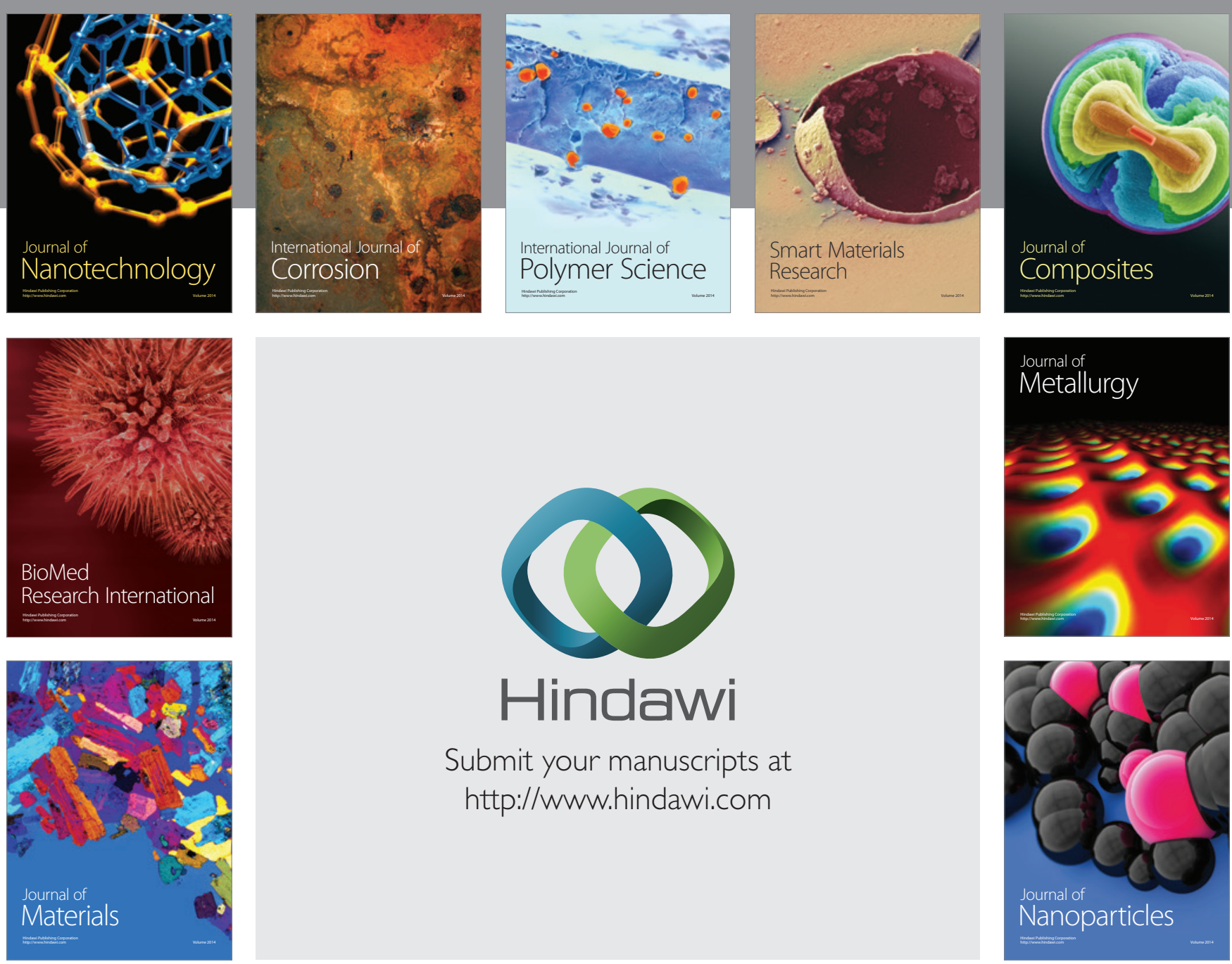

Submit your manuscripts at http://www.hindawi.com
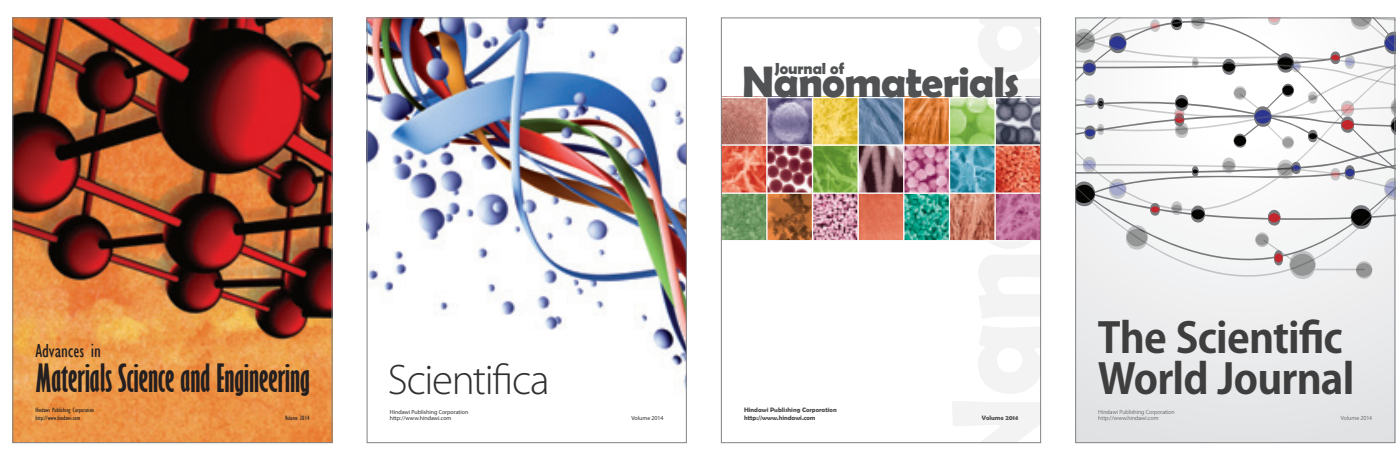

\section{The Scientific World Journal}
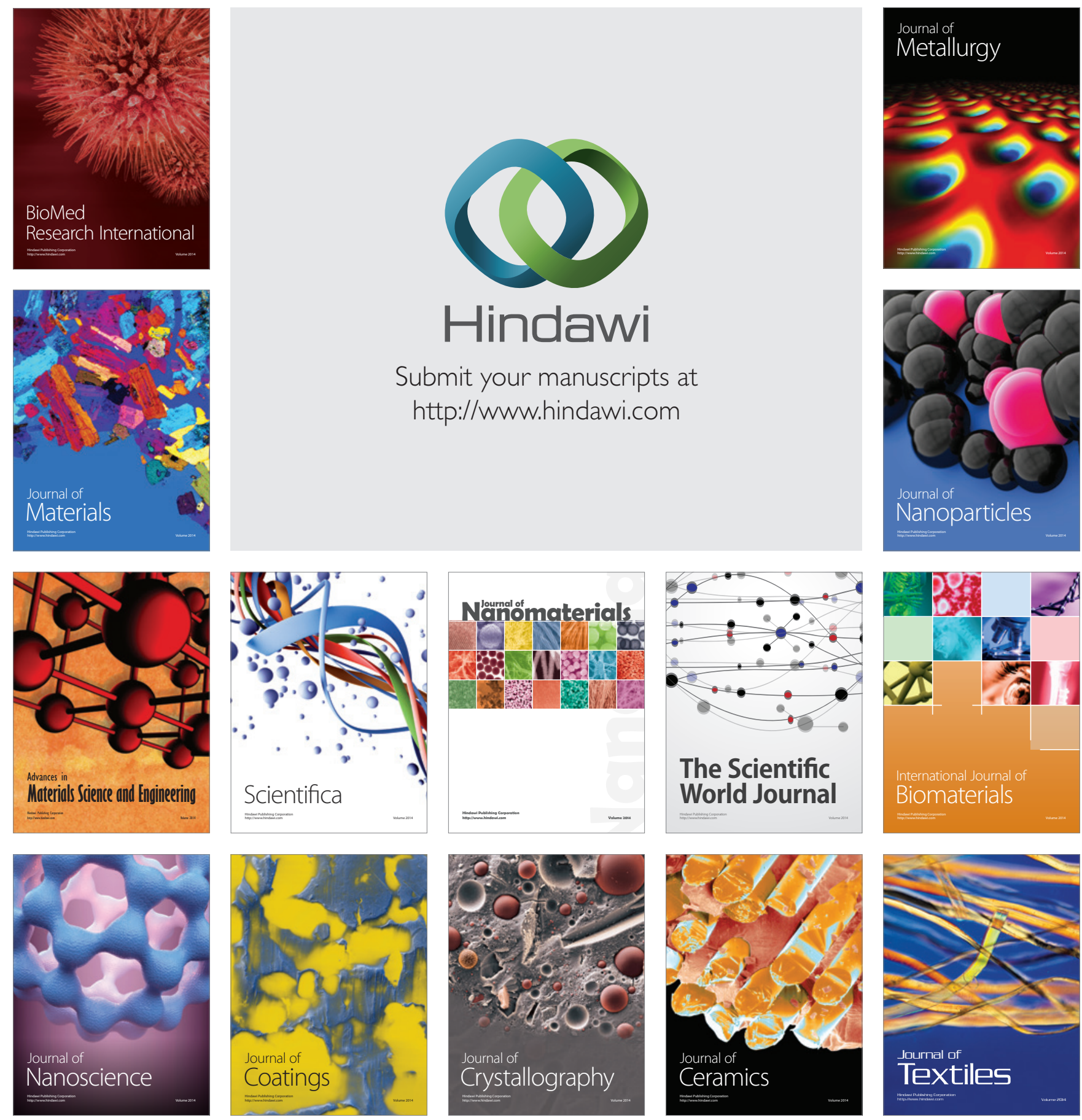